Journal of

Accident and

Emergency

Medicine 1994

$11,33-42$

\title{
Use of a pro forma for head injuries in the accident and emergency department - the way forward
}

\author{
S.A. WALLACE, ${ }^{1}$ R.W. GULLAN, ${ }^{2}$ P.O. BYRNE, ${ }^{3}$ J.BENNETT ${ }^{1}$ \& \\ C.A. PEREZ-AVILA 4 \\ ${ }^{1}$ Department of Public Health Medicine, A Block, Brighton General Hospital, Elm Grove, Brighton. \\ ${ }^{2}$ Department of Neurosurgery, The Brook General Hospital, Shooters Hill Road, London. \\ ${ }^{3}$ Midland Centre for Neurosurgery and Neurology, Holly Lane, Smethwick, Warley, West Midlands. \\ ${ }^{4}$ Deparment of Accident and Emergency Medicine, The Royal Sussex County Hospital, Eastern Road, \\ Brighton.
}

The aim of this study was to assess the quality of documentation of head-injured patients seen in three accident and emergency (A\&E) departments using a specially designed head injury pro forma. A 4-week prospective study of a single head injury pro forma was followed by a second similar study with an improved version (two head injury pro formas, one for young children and babies, the other for older children and adults). The main outcome measures were the degree of completion of the pro forma and questionnaire responses from receptionists, nurses and doctors. A total of 1260 patients had their details completed on the pro forma in both studies. Compared with standard hand written A\&E notes, the degree of completion of clinical details specific to the head injury were high, eg. over $95 \%$ for symptoms. The pro forma was generally well received by A\&E staff, particularly after recommended improvements were made, and the majority of staff felt it should be introduced permanently into the A\&E department. Concern about its use in cases of very minor head injury and multiple injuries were raised. As well as improved documentation, the pro forma facilitates the process of audit and may have an important role to play in information technology and computers in the future.

Key words: head injury, pro forma, quality of documentation.

\section{INTRODUCTION}

The quality of medical records has been much Correspondence: Dr Simon A. Wallace 46 Eaton Place, Brighton, East Sussex BN2 1EG

clinical detail of their content, but also for their legibility. ${ }^{1-4}$ This has been demonstrated previously in two of the three A\&E departments

\section{SUMMARY}

reviewed in this study, ${ }^{5}$ where the lack of information made it difficult to determine whether patients seen in the A\&E department had been managed appropriately according to a set of predetermined criteria.

Without clear and detailed medical records, many problems can arise. For example, medical and nursing staff may be unaware of the diagnosis and management plan of a patient who has been seen previously by another doctor, the job of coding clerks and the process of audit is more difficult, and more seriously, inaccurate or incomplete documented A\&E and admission details could lead to litigation and claims which are indefensible. ${ }^{6}$

As the result of a recent audit, ${ }^{5}$ and in conjunction with the South East Thames Regional Head Injury Working Party, ${ }^{7}$ a recommendation was made to develop a head injury pro forma for use in the A\&E department. The objectives involved in its use are shown in Table 1.

The degree of completion, opinions and com-

Table 1. Objectives of the head injury pro forma

(1) To replace the standard method of documentation for all patients seen in the A\&E department with a head injury.

(2) To include all the reception, nursing, observation and medical data on one piece of paper.

(3) To have preset stems, with boxes for ticking 'Yes', 'No' or 'Unsure' responses, keeping free text to a minimum.

(4) To guide A\&E staff through the assessment of a head-injured patient logically, help with decision making and allow a more 'uniform' management strategy for this large group of patients $(11 \%$ of all new A\&E attenders) ${ }^{24}$ 
S.A. Wallace et al. ments of receptionists, nurses and doctors were analysed prospectively. As a result, several changes to the layout and content of the pro forma were made and the same study was repeated.

\section{METHODS}

The layout of the pro forma was developed by a neurosurgeon an A\&E doctor and a public health physician in response to a form concept recommended by the Royal College of Surgeons. ${ }^{8}$ Advice and input was sought from other neurosurgeons, A\&E staff, general surgeons, orthopaedic surgeons and paediatricians.

Head injury patients of all ages seen in three A\&E departments in South East Thames Region had their demographic, nursing, observation and medical details completed on the pro forma over a 4-week period. All reception, nursing and medical staff were fully briefed. As two of the administration systems were not computerized and one was computerized (the Unisys A\&E computer system), appropriate guidelines for using the pro forma were developed.

Each section of the pro forma was analysed to assess the degree of completion and the results were tabulated using the Statistical Package for the Social Sciences (SPSS). Details of the patient's occupation and a history of alcohol consumption were not included in the assessment for children under 16 years of age. Similarly, details for posttraumatic amnesia, headache, nausea and visual disturbance were not included for children under 5 year of age.

A questionnaire was sent to all doctors, nurses and receptionists to assess their views of the pro forma, improvements that could be made and whether they would want it to be introduced on a permanent basis.

With the recommended changes that arose from the first study, a similar 4-week prospective analysis was performed on the improved version of the pro forma, which was expanded to two pro formas; one for adults and children of 6 years and over and the other for babies and children of 5 years and under (the former was green and the latter red for ease of identification). As before, both the degree of completion of the forms and the questionnaires that were sent to all staff were assessed.

The final versions of the pro formas are illustrated (in part) in the Appendix.

\section{RESULTS}

\section{First study}

A total of 684 patients with a head injury were documented on the single version of the pro forma at three hospitals over a 4-week period in 1990. Of these, $308(45 \%)$ were under 16 years of age.

Degree of completion. Figure 1 demonstrates that details of the symptoms specifically related to the head injury were complete in over $95 \%$ of all the patients' seen. Details of the patients' occupation $(77 \%)$ and the cause of the head injury $(66 \%)$ were not completed to the same extent. The degree of completion of details of specific examination signs related to the head injury were similarly high, as was completion of diagnosis and management details $(83 \%)$. Occasionally, details of the diagnosis and management were omitted from the pro forma, but were written on the standard A\&E card, because the patient had sustained more than a head injury and there was not sufficient room to document this on the pro forma (an initial design fault which was rectified in the second study period).

Figure 2 assesses the degree of completion of the observation chart, which was mainly completed by the nursing staff. Completion of this part was not as high.

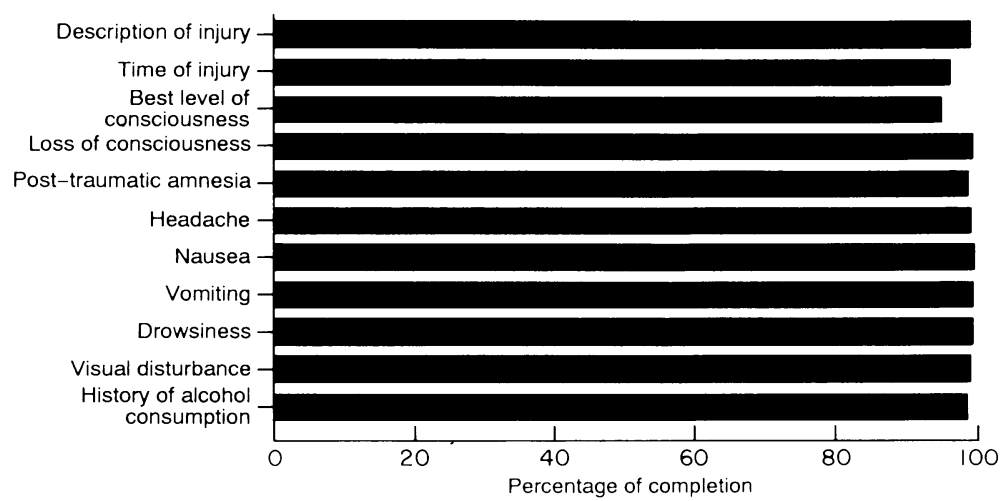

Fig. 1. Percentage of completion of head injury history details (July/ August 1990). 
Use of a pro forma for head injuries
Questionnaires. The general response from the A\&E staff was one of enthusiasm and support for the concept of the pro forma. It made little difference to the procedure in reception, although there was a general concern about arrangements for filing and a specific concern from the non-computerized $A \& E$ departments about the lengthy process of photocopying the pro forma to send to general practitioners. As a consequence, it was decided that a short hand-written note would be a better alternative. Finally, reception staff suggested that space for details about the name of the school, heaith visitor and social worker should be included for children with the other demographic details.

The nursing staff found it convenient to have the observation chart as an integral part of the main form. However, the major problem with the pro forma was the lack of space for the nursing assessment, thus generating a second piece of paper and jeopardizing the objective of all details contained within one document. There was also concern about the need for a full set of observations [Glasgow Coma Score (GCS), pulse, blood pressure, temperature, pupil size, limb movement and respiration] on all minor head injuries; this may explain the low degree of completion for some of these measurements. A final criticism of the form was the difficulty in use of the $\mathrm{GCS}^{9}$ and limb movement scales on babies and young children.

The overall response from A\&E doctors was very encouraging, demonstrated by the high degree of completion of the boxes in the history, examination and management sections. From the general comments, it was felt that the pro forma was quicker, more efficient and an easier method of assessment for patients with head injury. It ensured that all the relevant questions were asked and that the essential parts of the neurological examination were not missed. It was also felt to be a safe and uniform approach for junior doctors to adopt for the assessment and management of this category of patient.

Constructive criticisms were made which helped to improve the quality and practicality of the pro forma. These included the need for a separate form for babies and young children, and the need for space to document details of other injuries. The pro forma for young children and babies needed more relevant questions in the history section; the removal of questions about post-traumatic amnesia, visual disturbance, nausea and alcohol consumption and inclusion of questions about irritability on handling, inappropriate behaviour/play, decreased eating and drinking and a reminder of the possibility of nonaccidental injury. Likewise, aspects of the neurological examination needed tailoring to the young child and babies' neurological maturity, as did the GCS and the limb movement sections on the observation chart.

As a result of these and other suggestions from neurosurgeons, A\&E doctors, surgeons and paediatricians, two pro formas were subsequently designed; one for adults and children of 6 years and over and one for babies and children of 5 years and under, as illustrated (in part) in the Appendix.

\section{Second study}

In this study, there were 576 patients with a head injury at three hospitals who had their details completed on two head injury pro formas over a 4-week period in 1991. Of these $115(20 \%)$ were aged between 6 and 15 years of age and $164(28 \%)$ were aged 5 years or under.

Degree of completion. The degree of completion of details of symptoms, examination and management were similar in this study in 1991 and the first study in 1990.

Questionnaires. Overall, the revised head injury

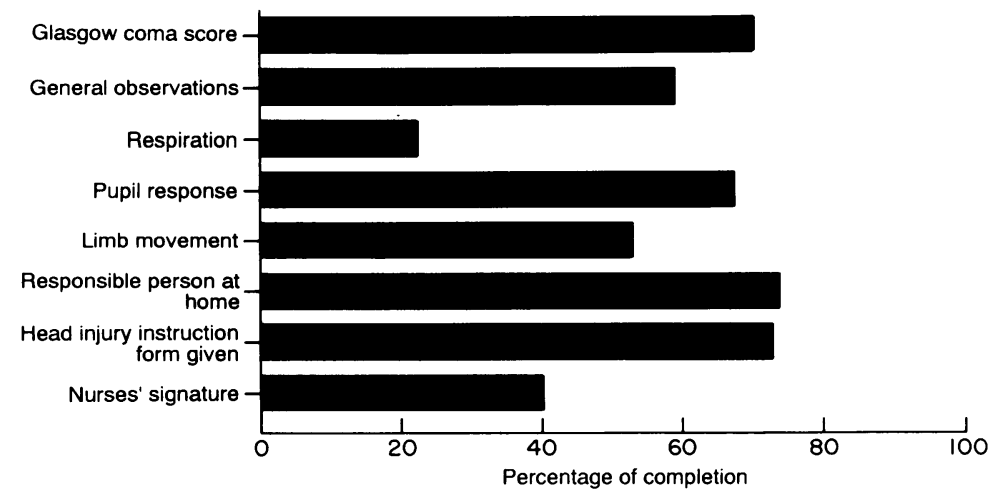

Fig. 2. Percentage of completion of nursing observation details (July/ August 1990). 
S.A. Wallace et al. pro formas were well received by the A\&E staff. The use of two pro formas for different age groups, the inclusion of space for the nursing assessment and the space for documentation of other injuries were all felt to improve the quality and application of the form. Two concerns were raised. Firstly, the use of such forms for the very trivial head injury and secondly, their use in the patient with severe multiple injuries.

Despite these concerns, of the 27 qualified nurses who completed the questionnaire, 19 (70\%) felt it should be introduced permanently to the A\&E department, six $(22 \%)$ were unsure and two $(8 \%)$ felt that it should not be introduced. Of the 38 A\&E doctors from both studies who completed the questionnaire, $32(84 \%)$ stated that the pro forma should be introduced into the A\&E department on a permanent basis, four (11\%) were unsure and two $(5 \%)$ felt that it should not be introduced permanently.

\section{DISCUSSION}

Several studies ${ }^{1-4}$ have highlighted the poor quality, both in content and legibility, of medical documentation and the resulting need for improvement. Recent work in two A\&E departments in Brighton has emphasized this problem with head injuries in particular. ${ }^{5}$ The development of the head injury pro formas has attempted to address this issue. In an already paper dominated administrative system, it has attempted to reduce the amount of paper used by incorporating the standard A\&E card, the observation chart and other nursing and medical documentation onto a single piece of paper as illustrated in the Appendix.

At the same time, the pro forr las have attempted to simplify and standardize the way in which a headinjured patient is assessed in the A\&E department. Set stems with tick boxes in the history, examination and management sections have been used to ensure that all the relevant issues are addressed, keeping free text to a minimum and thus hastening documentation.

The original pro forma, used in the first study, had been designed by a small number of health professionals. As a result of the two pilot studies, over 100 doctors, nurses and reception staff from various $A \& E$ departments have had an input to structuring the final version (see Appendix), not only to meet their own particular needs, but also to allow the pro formas as much versatility in their application as possible. This has created a sense of ownership, a greater understanding of their potential use in the
A\&E setting and has avoided the resistance that may arise at any stage in the process of developing and implementing new forms.

This standardized approach also acts as an educational tool for junior doctors who have recently started in A\&E and may have minimal experience with this clinical problem. This was emphasized by junior doctors feeling that the pro formas ensured that all relevant questions had been asked, resulting in greater confidence in their diagnosis and subsequent management. Indeed, it is hoped that with the chosen stems in the pro formas, the decisionmaking process of diagnosis, ordering of a skull radiograph and admission will be made easier and relate to guidelines that a particular A\&E department may be using.

Radiological investigation is expensive and may be overused ${ }^{10-13}$ and patients can be admitted unnecessarily. ${ }^{14-16}$ Thus, relevant clinical information needs to be sought and documented in order to improve management and use resources effectively.

Threat to clinical freedom has not been jeopardized. Firstly, there is adequate room for free text within the pro formas and secondly, the A\&E staff can use them to accommodate their own particular needs as and how it suits them. The pro formas have been created as an aid to staff looking after head-injured patients in A\&E and not as a list of rules.

Quality and content of medical documentation has also been improved. Figure 3 compares the degree of completion of symptoms and signs between an audit ${ }^{5}$ (i.e. hand-written notes) and this study (i.e. using the pro forma). Only loss of consciousness was well recorded in the 'hand-written' notes. ${ }^{5}$ It can be postulated that by having a more structured approach, a more thorough and complete consultation is achieved, while also allowing the important negative symptoms and signs to be documented. In fact, the use of such structured forms has not only been shown to improve the quality of information obtained, but also to improve the clinical response to certain risk factors. ${ }^{17}$

The effect of completing the pro formas on quality of patient care has not been assessed as this would require very large numbers of cases to be analysed against a suitable control group. However, this challenge is being addressed.

The advantages of good quality medical records should not be overlooked. As well as ensuring easier follow-up and clinical coding, the legal benefits of a standardized, medically accepted and legible 
Use of a pro forma for head injuries

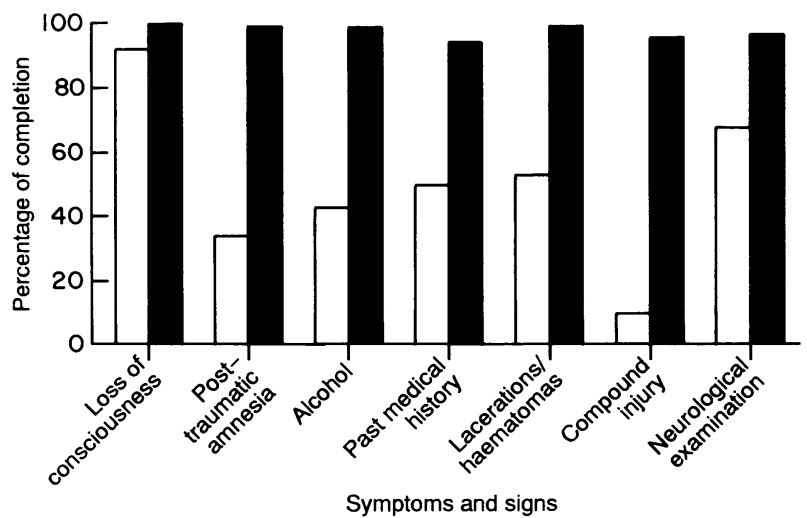

Fig. 3. Comparison of the degree of completion of symptoms and signs between the audit study (1989) and the pro forma study (1990), $\square$ denotes audit study and $\boldsymbol{\|}$ denotes pro forma study. format for head injury management are important. ${ }^{6}$ Epidemiological studies of head injuries can be more comprehensive. This will help both planning for provision of services ${ }^{18}$ and efforts to achieve the accident targets in the Government's White Paper, The Health of the Nation. ${ }^{19}$

Due to the success of both pilot studies, nine A\&E departments in the South East Thames Region have started using the head injury pro formas. A specially written Accident and Emergency Head Injury Proforma Guide ${ }^{20}$ was issued to all staff. It explains the concepts and clinical importance of each section of the pro formas and also acts as a simple $A B C$ of head injury management for both nurses and doctors.

It is critical to stress that the pro formas are an aid, not a dictate. From the outset, the concept of these forms has centred upon the most common type of head injury seen in the A\&E department. They may not be required for absolutely trivial cuts to the head, providing one is not cutting corners. However, it is the patient with the 'minor' head injury, sent home from A\&E without continued neurological observation within a hospital setting, that is potentially at the greatest risk of delayed treatment of a subsequent intracranial haematoma. Fortunately, this event is rare. ${ }^{21}$ Likewise, the pro formas are not intended for use in the management of the rare multiply-injured patient in the resuscitation room setting, where quite different information is required.

Other conditions may be amenable to this concept, for instance patients presenting with an asthma attack, a hand injury, an eye complaint or a gynaecological problem. Work is presently being undertaken to address these areas.

The format of the pro formas could act as a template for a computerized A\&E card, even perhaps to the extent of developing a paperless medical records system. The use of computer-aided decision support in acute abdominal pain has improved diagnostic accuracy ${ }^{22}$ without transgressing professional, ethical or legal boundaries. ${ }^{23}$ Perhaps the same approach could be developed for head injuries.

In conclusion, one should strive for improved medical documentation of head-injured patients. One solution is the use of pro formas where the amount of free text is reduced to a minimum and the quality of data entry is improved. This approach permits the process of audit of this very common problem to be more accurately practised, hopefully leading to better quality of management in the future. Its success depends on the benefit it bestows upon patients and their carers, in this case the staff in A\&E departments. Although the pro formas go some way to achieving this, information technology may have an important part to play in the future.

\section{ACKNOWLEDGEMENTS}

Acknowledgement is due to $\operatorname{Dr} M$. Crouchman, Mr A. Alloway and the reception, nursing and medical staff of the Royal Sussex County, the Royal Alexandra Children's Hospital in Brighton and the Brook General Hospital in London for their cooperation and support during the study. The authors are grateful to Ms Gitta Horan for assistance with word processing during the preparation of this manuscript.

\section{REFERENCES}

1. Beers M.H., Munekata M. Storrie M. (1990) The accuracy of medication histories in the hospital medical records of elderly persons. Journal of the American Geriatric Society 38(11), 1183-1187.

2. Williams J.G., Kingham M.J., Morgan J.M. \& Davies A.B. (1992) Retrospective review of hospital patient records. British Medical Journal 300, 991-993.

3. Gabbay J. \& Layton A.J. (1992) Evaluation of audit of 
S.A. Wallace et al. medical inpatient records in a district general hospital. Quality in Health Care 1, 43-47.

4. Dawson K.P., Capaldi N., Haydon M. \& Penna A.C. (1992) The paediatric hospital medical record: a quality assessment. Australian Clinical Review 12(2), 89-93.

5. Wallace S.A., Bennett J., Pereza-Avila C. \& Gullan R.W. (1994) Head injuries in the accident and emergency department: are we using resources effectively? Journal of Accident and Emergency Medicine 11, 25-31.

6. Garfield J. (1991) Head injuries and litigation. Journal of the Medical Defence Union 1, 2-3.

7. South East Thames Regional Health Authority (1989) A Regional Policy. Care of patients with acute head injury in district general hospitals. South East Thames Regional Health Authonity, Bexhill-on-Sea.

8. Royal College of Surgeons of England (1986) Commission on the provision of surgical services. Report of the Working Party on Head Injuries. Royal College of Surgeons, London.

9. Teasdale G. \& Jennett B. (1974) Assessment of coma and impaired consciousness. Lancet ii, 81-84.

10. Royal College of Radiologists (1981) A National Study by the Royal College of Radiologists. Costs and benefits of skull radiography in head injury. Lancet ii, 791-795.

11. Evans K.T., Roberts C.J. \& Ennis E.W. (1983) Head injuries in adults. British Medical Journal 287, 1882-1883.

12. Fowkes F.G.R., Williams L.D., Cooke B.R.B., Evans R.C., Gehlbach S.H. \& Roberts C.J. (1984) Implementation of guidelines for the use of skull radiographs in patients with head injuries. Lancet ii, 795-797.

13. Royal College of Radiologists Working Party (1992) Influence of the Royal College of Radiologists' guidelines on hospital practice: a multicentre trial. British Medical Journal 304, 740-743.

14. Weston P.A.M. (1981) Admissio I policy for patients following head injury. British Journal of Surgery 68, 663-664.

15. Mendelow A.D., Campbell D.A., Jeffrey R.R., Miller J.D., Hessett C., Bryden J. \& Jennett B. (1982) Admission after a mild head injury: benefits and costs. British Medical Journal 285, 1530-1532.

16. Edna T.H. \& Cappelen J. (1984) Hospital admission for head injury. A prospective study in Trondelag, Norway, 1979-80. Scandinavian Journal of Social Medicine 12, 7-14.
17. Lilford R.J., Kelly M., Baines A., Cameron S., Cave M., Guthrie K. \& Thornton J. (1992) Effect of using protocols on medical care: Randomised trial of three methods of taking an antenatal history. British Medical Journal 305, 1181-1184.

18. Brookes M., MacMillan R., Cully S., Anderson E., Murray S., Mendelow A.D. \& Jennett B. (1990) Head injuries in accident and emergency departments. How different are children from adults? Journal of Epidemiology and Community Health 4, 147-151.

19. Department of Health (1992) The Health of the Nation: A Strategy for Health in England. Cm 1986. HMSO, London.

20. Gullan R.W., Wallace S.A. \& Byrne P.O. (1992) ACcident and Emergency Head Injury Proforma Guide (unpublished).

21. Mendelow A.D., Teasdale G., Jennett B., Bryden J., Hessett C. \& Murray G. (1983) Risks of intracranial haematoma in head-injured adults. British Medical Journal 287, 1173-1176.

22. McAdam W.A., Brock B.M., Armitage T., Davenport P., Chan M. \& de Dombal F.T. (1990) Twelve years experience of computer-aided diagnosis in a district general hospital. Annals of the Royal College of Surgeons of England 72(2), 140-146.

23. de Dombal F.T. (1989) Computer-aided decision support in clinical medicine. International Journal of Biomedical Computing 24(1), 9-16.

\section{APPENDIX}

The objectives of the pro formas are detailed in Table 1. Due to the different stages of neurological development at varying ages, two head injury pro formas with complimentary symptoms and signs for the different age groups have been developed.

\section{NOTE ADDED IN PROOF}

Since this study, an alternative version of the head injury pro forma has been produced. It is now contained on two sides of paper only in either an 8" or an $11^{\prime \prime}$ size. It has an adhesive strip down the left hand side so that it can be stuck permanently into the standard $A \& E$ notes, e.g. as a page in a computer generated $A \& E$ booklet. 

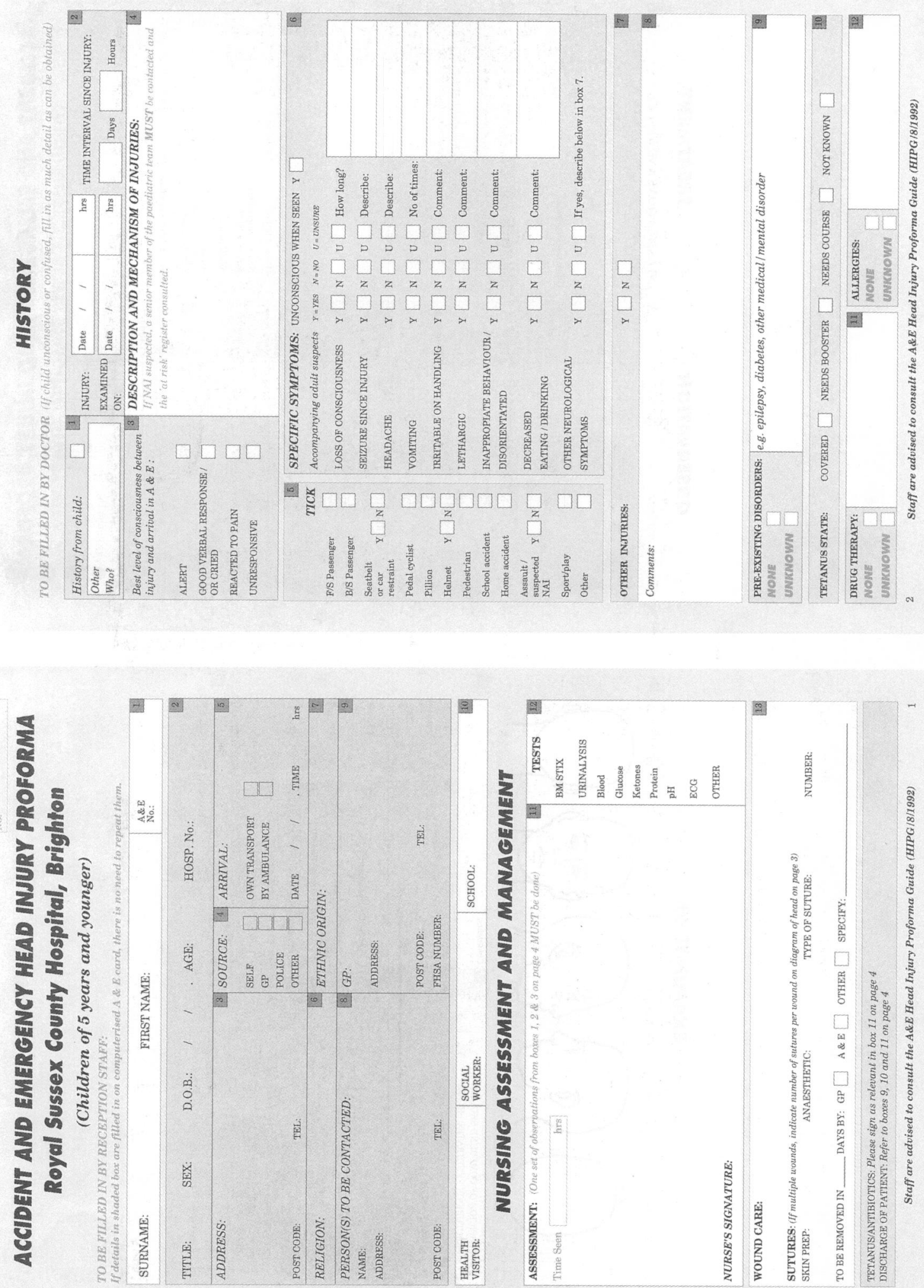

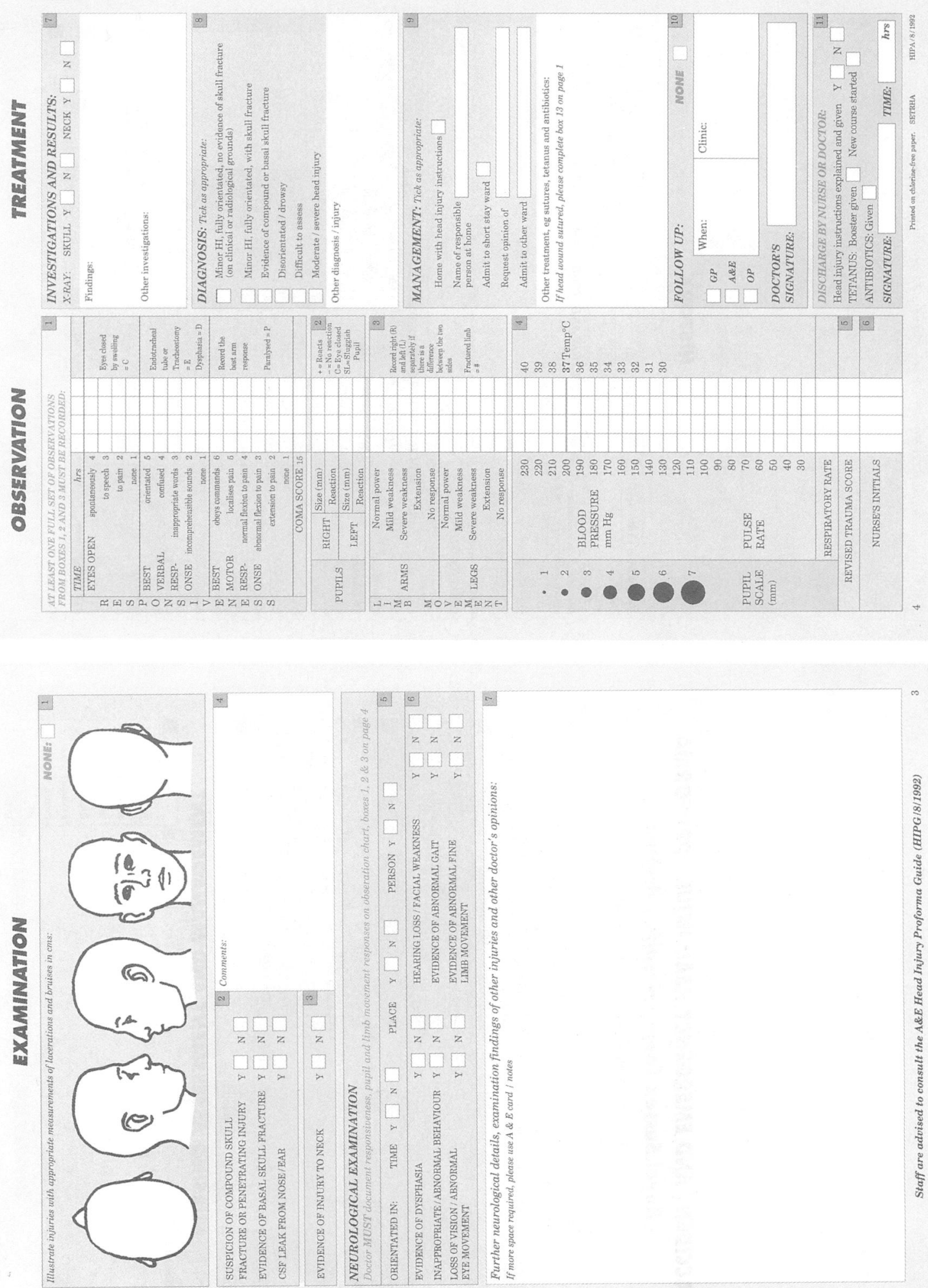

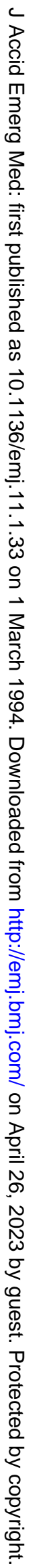


Use of a pro forma for head injuries
HEAD INJURY PRO FORMA FOR ADULTS AND CHILDREN OF

6 YEARS AND OLDER
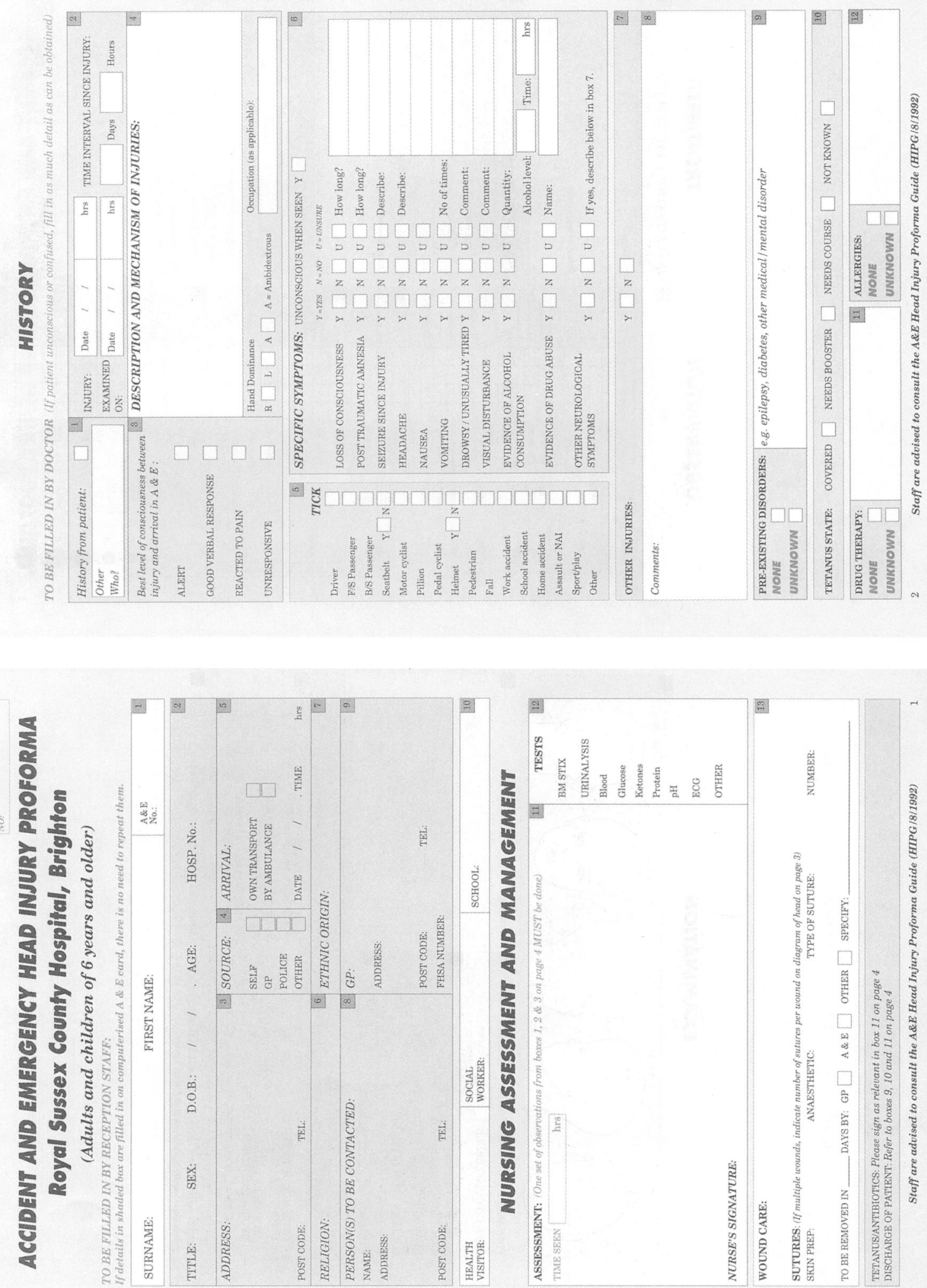


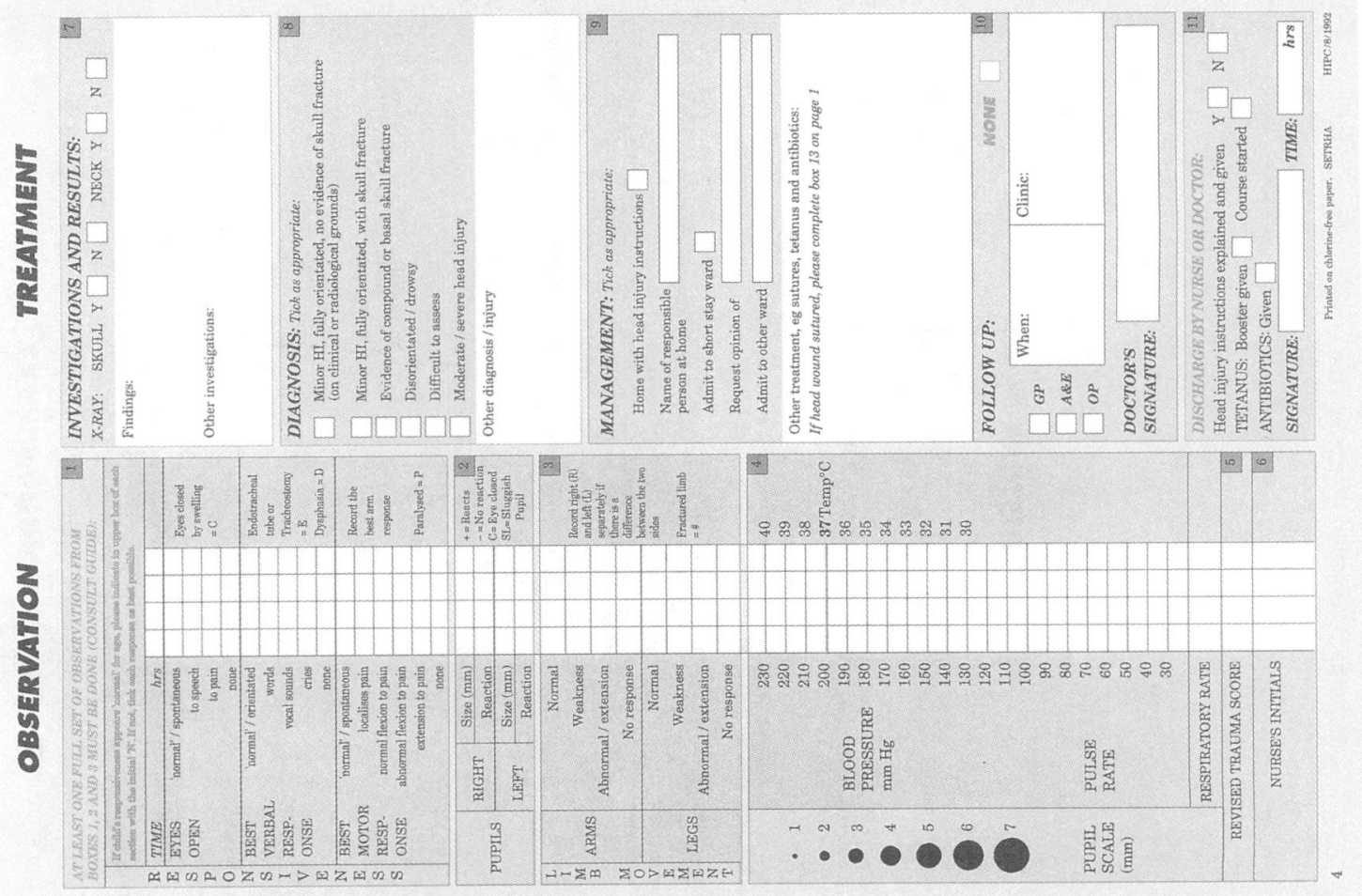

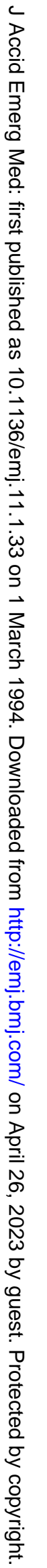

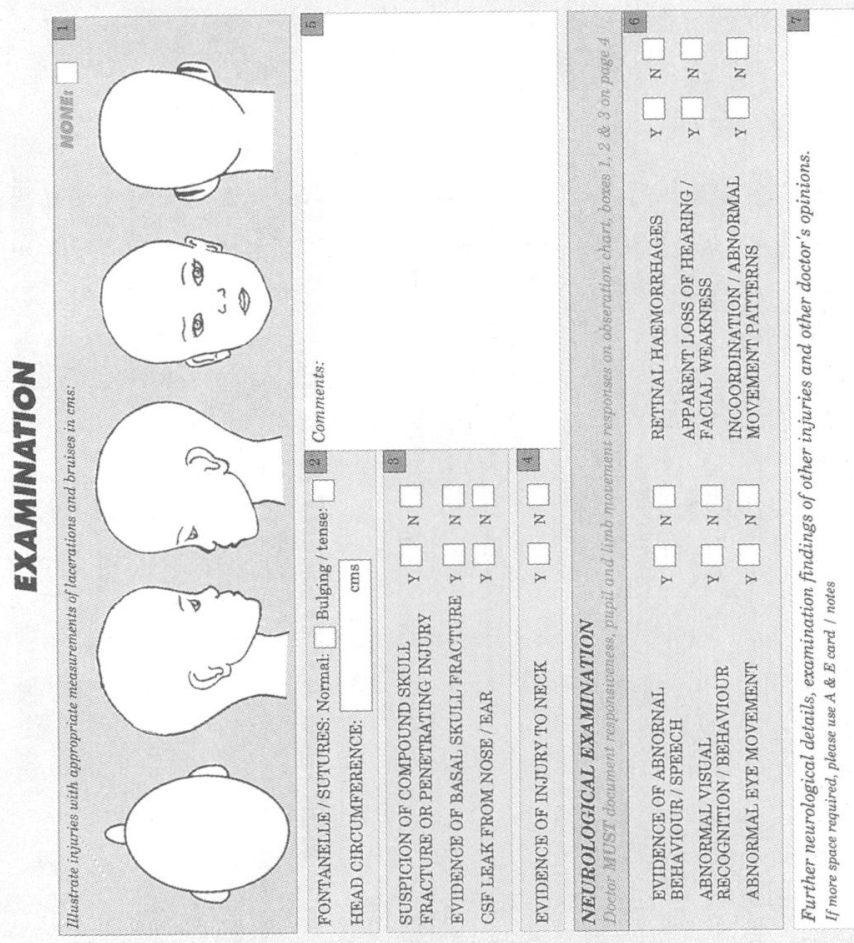

